\title{
Telomeres and telomerase in adrenocortical tissue maintenance, carcinogenesis, and aging
}

\author{
Tobias Else \\ Division of Metabolism, Endocrinology and Diabetes, MEND/Department of Internal Medicine, University of Michigan Health System, 1860 BSRB, 109 Zina Pitcher PI, \\ Ann Arbor, Michigan 48109-2200, USA \\ (Correspondence should be addressed to T Else; Email: telse@umich.edu)
}

\begin{abstract}
Telomere dysfunction and telomere maintenance mechanisms contribute to major steps of carcinogenesis. Dysfunctional telomeres lead to the generation of genomic aberrations, such as amplifications and deletions. Telomere maintenance mechanisms, such as telomerase activity and alternative telomere lengthening, provide the basis of malignant cell expansion independent of telomere shortening-induced apoptosis or senescence, ensuring tumor survival. Recent advances highlight the importance of these mechanisms in adrenocortical carcinogenesis. In this review, we will summarize the main models of telomere physiology and their impact on adrenocortical tissue maintenance, aging, and carcinogenesis.
\end{abstract}

Journal of Molecular Endocrinology (2009) 43, 131-141

\section{Overview}

Mammalian chromosomes end in a stretch of TTAGGG nucleotide repeats known as telomeres. There are two key challenges inherent to these structures. First, telomeres need to be protected from being recognized as a form of damaged DNA by the DNA surveillance and from being processed by the DNA repair machinery. Second, the semi-conservative DNA replication machinery does not entirely copy linear chromosomes, leading to a loss of terminal sequences and telomere shortening over consecutive cell divisions in the absence of a specific mechanism to restore these sequences. Physiological processes have evolved to meet these challenges. The recognition of telomeres as double strand breaks (DSBs) is prevented by a specialized DNA structure and a dedicated complex of proteins bound to the telomere. Cells reaching a critically short telomere length or harboring otherwise dysfunctional telomeres are effectively removed from the pool of proliferating cells through induction of apoptosis or senescence. Dysregulation of either of these protective processes can lead to acquisition and maintenance of a malignant phenotype. Malignant transformation as well as ongoing acquisition of malignant characteristics can be initiated by the accumulation of genomic alterations caused by telomere dysfunction-induced breakage fusion bridge cycles (BFBs). An indefinite potential of expansion of malignant cells can be secured by the acquisition of telomere length maintenance mechanisms (TMMs), which prevent telomere shortening, either telomerase activity (TA)-dependent or TA-independent alternative mechanisms of telomere lengthening (ALT).

Here, we will give insight into the current understanding of how these problems are solved physiologically and how they are exploited by malignant cells, specifically those of adrenocortical origin. We will focus on how telomere-protective mechanisms under normal physiological circumstances prevent the accumulation of chromosomal aberrations, how defects in these processes lead to the acquisition of a pro-cancer genome, and how TMMs ensure tumor survival. We will summarize what implications these mechanisms bear for adrenocortical cancer (ACC) and discuss implications of telomere physiology in tissue maintenance and aging of the adrenal cortex.

\section{Telomere physiology, telomere protection, and telomere dysfunction}

It has long been known that human fibroblasts cease to divide after $\sim 50$ cell divisions, a limit known as the Hayflick limit (Hayflick \& Moorhead 1961, Hayflick 1965). One reason for this is believed to be the 


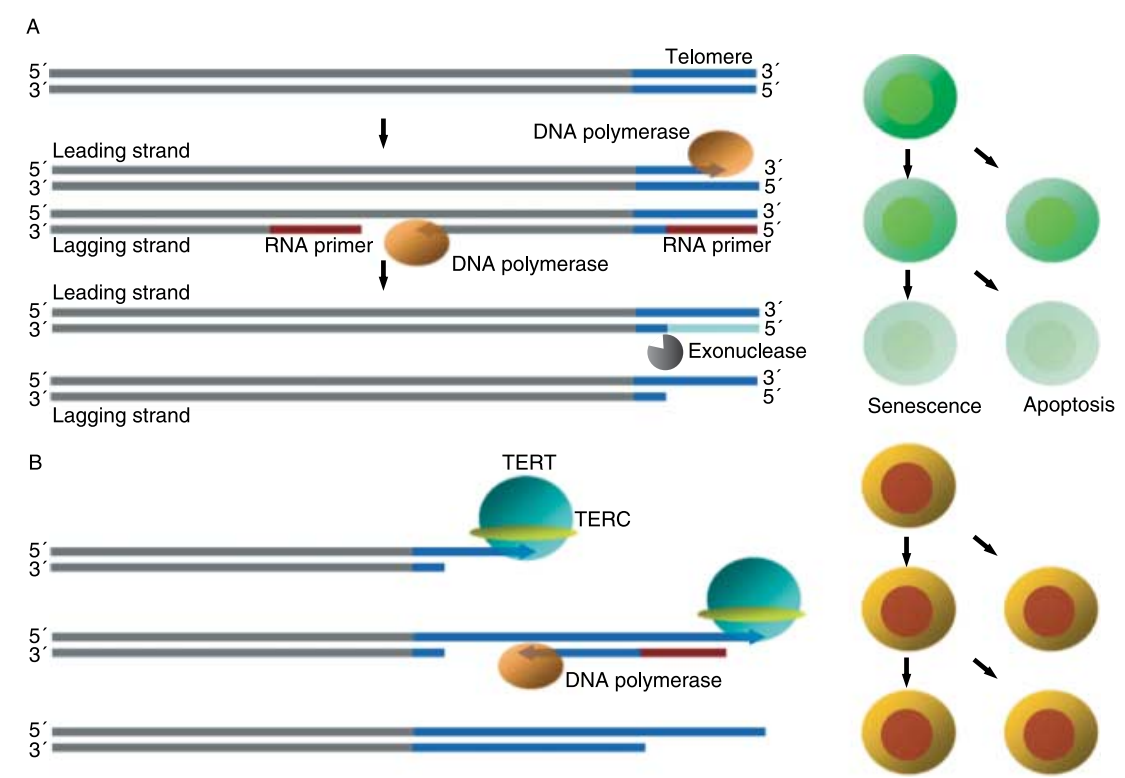

Figure 1 Model of telomere shortening and telomerase activity. (A) Telomere shortening. A $3^{\prime}$-overhang is created by the lagging strand synthesis after excision of the RNA primer resulting in a shortened telomere. $3^{\prime}$-synthesis of the leading strand can be carried to completion by the DNA polymerase. A $3^{\prime}$-overhang is created by a yet unidentified mechanism, most likely a $5^{\prime}$-exonuclease. After a certain number of cell divisions, telomeres become critically short and induce cellular senescence or apoptosis.

(B) Telomere maintenance. Telomerase, consisting of the protein (TERT) and RNA (TERC) subunit extend telomeres by adding telomeric repeats (TTAGGG) in the $3^{\prime}$-direction. The DNA polymerase can then synthesize the lagging strand. This process can maintain telomere length or lead to telomere lengthening.

progressive shortening of telomeres, a mechanism first theoretically proposed by Olovnikov in the early $1970 \mathrm{~s}$ of the last century (Olovnikov 1973). Due to the inefficiency of the semi-conservative replication carried out by DNA polymerases using RNA primers and the action of putative telomere-processing nucleases, short stretches of DNA at the chromosome ends get lost with each replication and eventually reach a critically short, dysfunctional state (Fig. 1A; Harley et al. 1990, Levy et al. 1992). Cells that must continue to divide for many generations, such as stem cell compartments within the skin, hematopoietic system, and male germ cells, prevent this shortening by the activity of the ribonucleoprotein enzyme telomerase (Taylor et al. 1996, Weng et al. 1996, Wright et al. 1996). Telomerase consists of two subunits, a protein component (TERT) that has reverse transcriptase activity and a ribonucleotide subunit (TERC) that harbors a template for TTAGGG telomeric repeats (Greider \& Blackburn 1987, Morin 1989). This enzyme adds telomeric TTAGGG sequences to the end of the telomere in the $5^{\prime}-3^{\prime}$ direction and subsequently DNA polymerases synthesize the lagging strand (Fig. 1B). TA is also an important marker of human embryonic stem cells (Thomson et al. 1998). Early in human adrenocortical development, TERC expression is restricted to the very outer zone of the emerging organ, probably marking the (prenatal) stem cell compartment (Yashima et al. 1998).

It is worthwhile to mention that murine cells display considerable differences in TA and telomere physiology. Rodent cells have much longer telomeres, TA is almost ubiquitously present in mouse organs, murine mouse embryonic fibroblasts (MEFs) undergo a stage of crisis as early as after eight to ten population doublings, and the progression to senescence is believed to be mainly driven by the accumulation of ongoing DNA damage as it can be prevented by low oxygen culture conditions (Kipling \& Cooke 1990, Prowse \& Greider 1995, Parrinello et al. 2003, Itahana et al. 2004).

Telomeres, the outer ends of chromosomes, by definition harbor an open end of DNA. This open end needs to be protected from being recognized by the very efficient DNA surveillance and repair machinery, which is charged with the tasks of ensuring integrity of the genome and removing cells with damaged DNA from a population. Indeed, eukaryotic cells have the ability to distinguish the end of a linear chromosome from a DSB by two interdependent mechanisms: 1) telomeres form a specialized DNA structure and 2) telomeres are tightly bound by a protein complex, the shelterin complex (Fig. 2A and $\mathrm{B}$ ). Telomeres form a loop structure (T-loop) in 
A

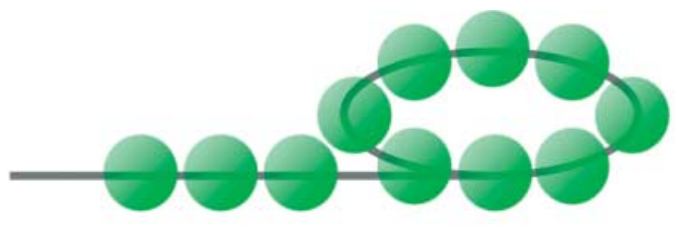

B

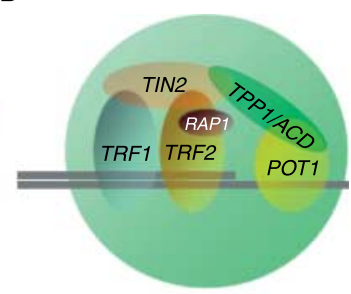

C

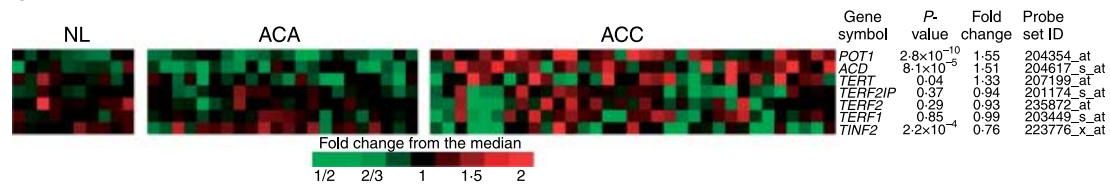

Figure 2 (A) Multiple shelterin complexes can be found at the telomere DNA T-loop and most likely exist in different compositions to serve the multiple functions of the telomere, protect it from recognition and processing by the DNA surveillance machinery. (B) Model of the telomere cap complex (shelterin complex) bound to the end of the telomere. (C) Data from a gene expression array (IDs refer to the HG-U133 Plus 2 array) of adrenocortical tumors. Fold change is expressed as ACC versus ACA and NL as one group. TERT, POT1, $T P P 1 / A C D$, and TIN2 are significantly differently expressed in malignant versus nonmalignant adrenocortial tissues. Official gene symbols are used in the array: POT1, protection of telomeres 1; $A C D$, adrenocortical dysplasia homologue (TPP1/ACD); TERT, telomerase reverse transcriptase; TERF2IP, TERF2-interacting protein (RAP1); TERF2, telomeric repeat-binding factor 2 (TRF2); TERF1, telomeric repeat-binding factor 1 (TRF1); TINF2, TRF1-interacting nuclear factor 2 (TIN2).

which the 3 '-overhang inserts into double-stranded telomeric DNA (Griffith et al. 1999). Six different core proteins binding either to telomeric DNA or serving as interconnectors between DNA bound proteins form the shelterin complex (de Lange 2005). TRF1 and TRF2 bind to double-stranded telomeric TTAGGG repeats, while POT1 also binds to the single-stranded 3'-overhang (Chong et al. 1995, Broccoli et al. 1997, Baumann \& Cech 2001). The remaining three components of this complex bind to DNA-bound factors and potentially form several possible configurations, which are proposed to serve different functions (Liu et al. 2004a). RAP1 binds to TRF2, TIN2 binds to TRF1 and TRF2, and TPP1/ACD serves as an interconnector between TIN2 and POT1 (Kim et al. 1999, Li et al. 2000, Houghtaling et al. 2004, Liu et al. 2004b, Ye et al. $2004 a, b)$. The telomeric DNA-protein complex has a dual function: it protects telomeres from being recognized as DSBs and regulates telomerase access to the telomere (de Lange 2005).

Dysfunctional telomeres, either critically short or lacking shelterin components, activate DNA damagesignaling pathways that ultimately lead to cellular senescence or apoptosis (Bodnar et al. 1998, Lee et al. 1998, Karlseder et al. 1999). These pathways exploit the same mechanisms that recognize DNA breaks and induce stalling of the cell cycle and potentially repair of the lesion (Artandi \& Attardi 2005). Deprotected telomeres can be visualized in cells as telomere dysfunction-induced foci (TIFs) by co-staining for factors such as $\gamma \mathrm{H} 2 \mathrm{AX}$ and p53BP together with telomere in situ hybridization using telomere-specific peptide nucleic acid probes (Takai et al. 2003). The recruitment of these immediate DNA damage factors leads to the activation of ATM/ATR, which in turn leads to p53 activation and increased levels of p21 (Brown et al. 1997, Karlseder et al. 1999). A parallel pathway leads to the expression of $p 16 / I N K 4 A$, which in human but not murine cells leads to a cell cycle arrest (Jacobs $\&$ de Lange 2005). These pathways ultimately lead to the withdrawal of cells harboring critically short or damaged telomeres from the pool of proliferating cells via apoptosis or senescence. Therefore, telomere damage signaling-induced senescence and apoptosis can be regarded as a cellular defense mechanism against malignant transformation, preventing the acquisition of genomic aberrations (Artandi \& Attardi 2005, Ju \& Rudolph 2006, Deng et al. 2008). Although the mechanism that determines in vivo the preference for induction of apoptosis or senescence is not well understood, there is evidence for cell type dependence, e.g. some epithelial cells and lymphocytes tend to preferably undergo apoptosis and fibroblasts preferably progress to senescence (Karlseder et al. 1999).

Telomere dysfunction-induced apoptosis and senescence function to prevent the accumulation of genomic aberrations. Telomere dysfunction in $p 53$ proficient cells leads to cell cycle arrest, senescence, and apoptosis (Karlseder et al. 2003). By contrast, in the setting of $p 53$ deficiency, dysfunctional telomeres are processed by 


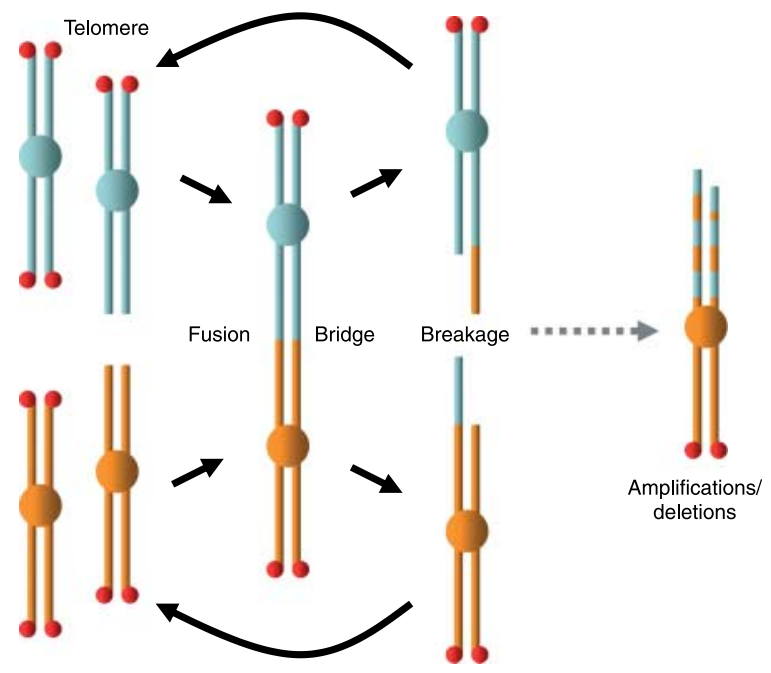

Figure 3 Model of genomic shuffling by breakage fusion bridge (BFB) cycles. Dysfunctional telomeres (absent red circles) fuse and form dicentric chromosomes. During cell division, the fused chromosomes are pulled to the two different poles of the emerging daughter cells. During anaphase these can be observed as anaphase bridges, chromosomal material spanning from one daughter cell to the other. Eventually, a break occurs and creates another open end, which can serve as a new starting point for a subsequent BFB. Ultimately, this process leads to genomic amplifications and deletions.

the DNA repair machinery (Attardi 2005). Dysfunctional telomeres are processed via end-to-end fusions to form dicentric chromosomes. In accordance with this mechanism, dicentric chromosomes have been found in telomerase-deficient cells as well as in MEFs from Pot1-deficient animals and from adrenocortical dysplasia $(a c d)$ mice, which harbor a mutation in the Tpp1/Acd gene (Hande et al. 1999, He et al. 2006, Hockemeyer et al. 2006, 2007, Wu et al. 2006, Else et al. 2007). Dicentric chromosomes lead to an oncogenic mechanism of genome shuffling, which is known as breakage fusion bridge (BFB) cycles (Fig. 3; Artandi et al. 2000, Lo et al. 2002, Murnane \& Sabatier 2004, Murnane 2006). Over subsequent cell divisions, the two free ends of a dicentric chromosome are pulled to the different poles of the emerging daughter cells. In tissue sections and cell culture, these structures can be observed as anaphase bridges, chromosomal material spanning the nuclei of the two emerging daughter cells. Interestingly, this morphological correlate was observed in malignant tumors as early as 1891 (Hansemann 1891). These bridges of chromosomes will eventually break and newly expose open ends that can serve again as starting points for a BFB. The break does not necessarily take place at the former fusion site, but can take place anywhere in the chromosome, although it is likely that specific 'weak' areas exist, which are predisposed to serve as a breakage site. This process leads to translocations, regional genomic amplifications, and genomic losses that can be visualized by spectral karyotyping and estimated by comparative genomic hybridization (Artandi et al. 2000, O'Hagan et al. 2002, Else et al. 2007). BFBs can serve as a mutagenic mechanism leading to the amplification of oncogenes and the loss of tumor suppressor genes. It is important to keep in mind that under normal circumstances cells harboring dysfunctional telomeres, which can serve as initiators of BFBs, are efficiently removed by apoptosis or senescence. Most models examining the sequelae of dysfunctional telomeres, therefore, make use of cellular and animal models deficient in the major components of the DNA damagesignaling machinery, such as p53 (Fig. 4). It is worthwhile mentioning that TA or TMMs (as opposed to their function described below) can act as a cancer preventive mechanism in this model. At least in the case of telomere shortening-induced telomere dysfunction, TMMs can obviate the occurrence of dysfunctional telomeres as starting points for BFBs (Hornsby 2007).

\section{Dysfunctional telomeres in carcinogenesis and $A C C$}

As described, dysfunctional telomeres, either short or decapped, can result in genomic alterations through BFBs over multiple cell divisions. Evidence that dysfunctional telomeres lead to increased carcinogenesis stems from animal models, mainly using late generation TERC-deficient mice, which develop

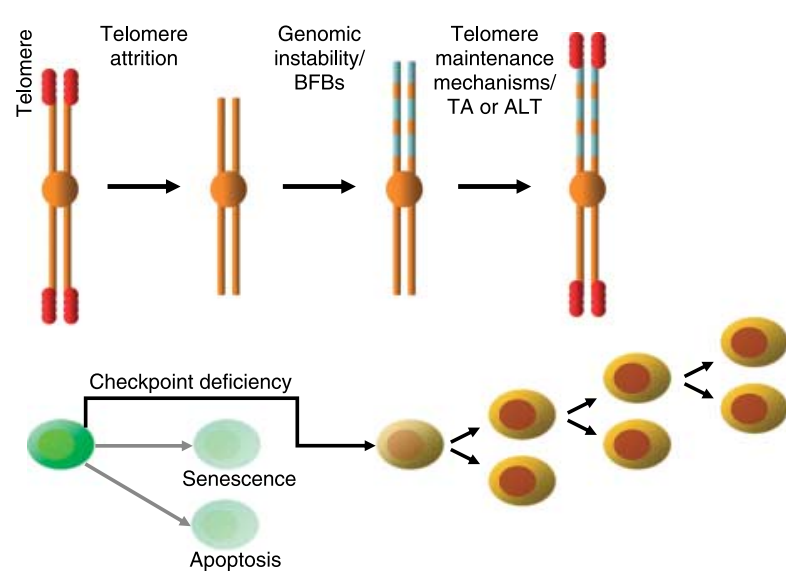

Figure 4 Telomere-focused model of tumorigenesis. Dysfunctional telomeres, either as a consequence of telomere decapping or resulting from telomere shortening, will be recognized by the DNA surveillance machinery and induce senescence or apoptosis (telomeres are shown as red circles). In the setting of checkpoint deficiency, such as p53 deficiency, chromosomes may fuse and start BFBs, leading to a shuffling of the genome and genomic amplifications and deletions. This first step generates a procancer genome. In a second step, chromosomes are stabilized by telomere length maintenance mechanisms (either TA or ALT) and the emerging cancer cells acquire independence of telomere shortening-induced senescence or apoptosis. 
critically short telomeres due to the absence of TA (Blasco et al. 1997). Breeding these mice to a p53-deficient background results in a significant increase in tumor incidence compared with $p 53$ deficient, but telomerase-proficient mice (Chin et al. 1999). Two human syndromes underscore the role of telomere dysfunction in human carcinogenesis: dyskeratosis congenita (DC) and Li-Fraumeni syndrome. DC patients whose genome harbors mutations in genes encoding telomerase (TERC or TERT), shelterin components (TIN2), or a telomerase-processing protein (DKC1) are predisposed to develop early cancers, presumably induced by critically short dysfunctional telomeres (Heiss et al. 1998, Vulliamy et al. 2001, Armanios et al. 2005, Savage et al. 2008). The majority of Li-Fraumeni syndrome is caused by $p 53$ mutations (Malkin et al. 1997). It is noteworthy that ACC is one of the common syndrome-defining malignancies (Li et al. 1988). A recent study links carcinogenesis in Li-Fraumeni syndrome to telomere shortening (Tabori et al. 2007). In family analyses of affected and unaffected p53 mutation carriers, telomere length was significantly shorter in patients who develop malignancies, arguing for an involvement of telomere dysfunction in carcinogenesis in Li-Fraumeni syndrome (Tabori et al. 2007, Tabori \& Malkin 2008).

Some recent reports suggest the participation of genes encoding shelterin complex components in spontaneous human malignancies. Studies focusing on B-CLL found expression levels of TRF1, RAP1, and POT1 significantly decreased and of TPP1/ACD significantly increased (Poncet et al. 2008). In gastric cancer, POT1 expression levels correlate with tumor stage (Kondo et al. 2004). While these studies, as well as those focusing on other malignancies, do not display a common trend of up- or downregulation of single shelterin components (Bellon et al. 2006, Lin et al. 2006, Salhab et al. 2008), they show a common scheme of dysregulation of the complex. Recently, several series of gene expression arrays have been published, including some of ACC. In the dataset generated by Giordano et al. POT1 and TPP1/ACD are expressed at significantly higher and TIN2 at significantly lower levels in ACC vs ACA and normal adrenocortical tissue (POT1 1.6-fold, TPP1/ACD 1.6-fold, and TIN2 0.75-fold; all $P<0 \cdot 001$; Fig. 2C, Giordano et al. 2009).

\section{Telomere length maintenance mechanisms in ACC}

TMMs are regarded as crucial to ensure tumor survival. Roughly, $90 \%$ of human malignant tumors exploit the mechanism of TA to gain potential for indefinite clonal expansion without telomere shortening-induced apoptosis or senescence (Kim et al. 1994). Following the description of this phenomenon, a few malignant tumor entities emerged that did not display any considerable TA, but yet did not undergo crisis or progressed to senescence (Bryan et al. 1997). Analyses showed that these cell clones established ALT. The molecular bases of ALT are not well understood, but certain surrogate parameters correlate well with the presence of ALT. One parameter is stable, usually very long, telomeres with a wide range of length distribution. Another one is the immunocytochemical co-localization of very bright telomere in situ hybridization signals together with promyelocyte leukemia (PML) bodies (Bryan et al. 1997). The underlying mechanism of ALT is currently thought to be based on homologous recombination between telomeres (Muntoni \& Reddel 2005).

Most human cancers use TA as the primary TMM, but a significant percentage of certain tumor entities, such as liposarcomas or glioblastomas, have been shown to be telomerase negative (Hakin-Smith et al. 2003, Johnson et al. 2005, Costa et al. 2006). A considerable number of these tumors use ALT as their main TMM and in some tumors signs of both TMMs can be found. The data regarding TMMs in ACCs have been inconsistent, which is most likely due to differences in tissue collection, tissue storage, and analyses methods (Hirano et al. 1998, Kinoshita et al. 1998, Teng et al. 1998, Bamberger et al. 1999, Mannelli et al. 2000). It seems to be undisputed that a considerable number of ACCs are positive for TA (Orlando \& Gelmini 2001). Some studies also found TA in benign adrenocortical adenomas (Mannelli et al. 2000, Orlando \& Gelmini 2001). Interestingly, the first reports investigating ALT in different tumor cells included some ACCs, but, unfortunately, did not give any further pathological or clinical details (Bryan et al. 1997). As a result of our interest in exploring possible ALT mechanisms in ACC, we have recently carried out a survey of TMMs in adrenocortical benign and malignant tissues (Else et al. 2008). Tissue samples were obtained by a microdissection technique, collecting areas of morphologically proven tumor cells within frozen embedded tissues. Interestingly, virtually, all malignant samples tested in this study displayed evidence for at least one TMM, with the majority employing TA $(79 \%)$, a minority using both TA and ALT (8\%), and a small number displaying only surrogate parameters of ALT (4\%). None of the normal adrenal tissues or benign adrenocortical adenomas showed any signs of TMMs. All of the available ACG cell lines (SW13, RL251, NCI-H295R, and NCI-H295A) are positive for TA (unpublished results). NCI-H295R and NCI-H295A also display surrogate parameters for ALT, indicating a use of both mechanisms (Else et al. 2008). Although this study, like other previous reports, was entirely descriptive, one can conclude that the presence of TMMs is a special 
characteristic of malignant lesions and might further speculate that ACCs depend on the presence of a TMM to preserve a malignant phenotype.

Serial tumor cell transplantation experiments underscore the importance of TMMs for maintaining malignant behavior (Sun et al. 2004). SV40 large T antigen and RAS-transformed bovine adrenocortical cells loose their malignant potential over the course of serial transplantations of tumor cells into immunodeficient mice. Malignant behavior can be restored by introduction of TA (Sun et al. 2004).

\section{Shelterin components and tissue homeostasis and development}

All attempts to create mice completely deficient in any of the shelterin complex proteins, including Tin2, Trf1, and Trf2, have resulted in lethality early in development (Karlseder et al. 2003, Chiang et al. 2004, Celli \& de Lange 2005). Pot1 in the murine genome is considerably different as surprisingly two genes, Pot $1 a$ and Pot $1 b$, encoding two homologous proteins were found (Hockemeyer et al. 2006, Wu et al. 2006). While double knock-out mice share the phenotype of early lethality, Pot1b-deficient mice survive to adulthood (Hockemeyer et al. 2006). Therefore, most of our knowledge of the consequences of telomere dysfunction in adult murine life stems from Terc- and Tertdeficient mice, from the conditional Trf2-deficient mouse and from one spontaneous mouse mutant, deficient in $T p p 1 / A c d$, the so called adrenocortical dysplasia (acd) mouse (Lee et al. 1998, Liu et al. 2000, Lazzerini Denchi et al. 2006, Else et al. 2007). The acd mouse arose spontaneously on the background of the control strain $(\mathrm{DW} / \mathrm{J})$ for the pituitary dwarf mutation and it shares many phenotypic features with late generation Terc- and Tert-deficient mice (Beamer et al. 1994, Keegan et al. 2005). All three mutant strains display disturbed fur maintenance, are small and subfertile due to severe reduction in male germ cells (Lee et al. 1998, Liu et al. 2000, Keegan et al. 2005). The main difference between these animals is that the acd phenotype is apparent in the first generation, while Terc- and Tert-deficient mice must be bred over at least four to five generations to appreciate this phenotype. The molecular phenotype of dysfunctional telomeres in Terc- and Tert-deficient mice is acquired over multiple cell divisions and depends on the occurrence of critically short telomeres, while cells from acd mice show telomere dysfunction due to a severe deficiency of the shelterin component protein, Tpp1/Acd, already in the first generation. This reflects the two different molecular mechanisms by which telomere dysfunction is thought to be induced in these animal models. In the absence of telomerase telomeres reach a critical length and become dysfunctional by decreased binding of shelterin components to the telomere, while telomere deprotection in Tppl/Acd deficiency is immediately evident and does not depend on telomere shortening. A possible explanation for the absence of early embryonic lethality in acd mice is the hypomorphic character of the acd allele. The acd mutation is a splice site mutation and, as often is the case with naturally occurring mutants, either some wild-type protein is produced or some level of function is preserved in the protein leading to an amelioration of the phenotype. While translation of a functional protein from the mutated RNA is very unlikely for the acd allele, we were able to detect minimal amount of wtTpp1/Acd mRNA in acd MEFs. Presumably, this RNA originates from the usage of the 'original' splice site and the amount of translated wt protein is sufficient to bypass early lethality and allow some acd mice to survive to adulthood (Keegan et al. 2005). Although acd mice share common features with late generation mice lacking TA, there are some distinct differences. Interestingly, acd mice show a peculiar morphology of the adrenal cortex resembling human adrenal hypoplasia congenita (AHC) with cytomegaly. The adrenal cortex and medulla are not as clearly separated as in normal adult mice and, most strikingly, the adrenal cortex consists of large cells with a large eosinophil cytoplasm and cytomegalic pleomorphic nuclei that harbor eosinophilic nuclear inclusion bodies. There are at least two explanations for this particular morphology occurring in acd mice, but not in late generation Terc-deficient mice. First, as evidenced in the liver-specific inducible knock out of another shelterin protein, $\operatorname{Tr} f 2$, telomere fusions can result in endoreduplication and development of hyperploidy (Lazzerini Denchi et al. 2006). This explanation, however, would not explain why this phenotype is not observed in late generation Tercdeficient mice unless one assumes that telomere dysfunction in acd mice is different or less/more severe than telomere dysfunction induced by critically short telomeres. Another possibility is that cytomegaly may result from lack of an adrenal cortex-specific function of Tpp1/Acd, independent of its role in telomere physiology. At first glance this possibility seems to be unlikely, as no significant functions other than telomere regulation have been shown for shelterin components. However, recent data show that TERT, independent of its role in telomere physiology, participates in cellular signaling pathways and may impact Wnt signaling, a pathway crucial for adrenal development and tissue maintenance (Sarin et al. 2005, Choi et al. 2008, Kim et al. 2008, Venteicher et al. 2008).

AHC with cytomegaly has been well described in human pathologies. It is the pathomorphological hallmark of DAX1 mutations, Beckwith-Wiedemann syndrome, and IMAGe syndrome, but it also occurs 
spontaneously as shown by analysis of pediatric autopsies ( $\sim 0.8 \%$; Irving 1967, Favara et al. 1991, Zanaria et al. 1994, Vilain et al. 1999, Tan et al. 2006). In a recent study of IMAGe syndrome patients, no mutation in TPP1/ACD could be found, but other genes encoding shelterin complex members have not been examined (Hutz et al. 2006). One could speculate that some of the spontaneous cases of AHC with cytomegaly could be attributed to mutations leading to telomere dysfunction. AHC with cytomegaly may also represent a morphological correlate of cellular senescence. Indeed, cytomegalic cells in the acd adrenal cortex stain positive for several senescence-associated markers (unpublished data). AHC with cytomegaly may resemble the common morphological endpoint of several mechanisms, such as stem cell exhaustion.

\section{Telomeres, apoptosis, and senescence in adrenocortical physiology and aging}

Apoptosis and senescence can be induced by a myriad of stimuli. Apoptosis occurs under physiological circumstances in the adrenal gland at the border between cortex and medulla. The general paradigm of replenishment of the adrenal cortex starts with cell replacement from a putative peripheral stem cell zone, followed by an inward directed cell displacement and cell death at the innermost part bordering the adrenal medulla (Zajicek et al. 1986, Kim \& Hammer 2007). Therefore, it is reasonable to regard the observation of apoptosis in this area as a physiological mechanism of a constantly renewing organ. This mechanism is most likely independent of telomere dysfunction or shortening. Senescence in the adrenal cortex is less well understood, mainly due to the absence of reliable markers for senescent cells in general and in the adrenal cortex in specific.

The adrenal cortex undergoes significant age-related changes at the organ level. With age the zona reticularis disappears and dehydroepiandrosterone (DHEA) and dehydroepiandrosterone sulfate (DHEAS) production decreases (Hornsby 1995). Cellular senescence may contribute to this process as summarized in a recent review (Hornsby 2002). Assuming absent or insufficient TA in the adult human adrenal cortex, one might expect an age-related decrease in telomere length and, therefore, telomere dysfunction in the adrenal cortex, specifically in the self-renewing stem cell compartment. Recently, it has been shown that telomere length in adrenocortical cells is inversely correlated with donor age (Yang et al. 2001). Therefore, over time one would expect that the adrenal cortex would lose its stem or progenitor cells due to critical telomere shortening and dysfunction. These processes would be expected to take place in the peripheral stem cell zone. Under the circumstance of a decreased number of organ-specific progenitor cells, preservation of the vital functions of the outer zona glomerulosa $(=$ mineralocorticoid production) and zona fasciculata (=glucocorticoid production) may be ensured at the expense of the less vital functions of the innermost zona reticularis (=DHEA production). Senescent cells may also influence the steroidogenic profile through secreted senescence-associated factors. Recent microarray analyses have shown a distinct gene expression profile associated with senescence, including expression of some secreted factors (Shelton et al. 1999).

Senescence and stem cell aging are influenced not only by telomere shortening but also by ongoing accumulation of DNA damage, which may be more prominent at the telomere than other DNA sites (Richter \& von Zglinicki 2007). Reactive oxygen species have been implicated in age-associated changes in other steroidogenic tissues, such as Leydig cells and one might speculate that free radicals emerging as intermediate products of the process of steroidogenesis contribute to telomere and DNA damage and, in turn, to aging of the adrenal cortex (Hanukoglu 2006, Midzak et al. 2009). Overall, it is an interesting theory that the process started by cellular aging (cellular senescence) spreads via organ aging (loss of zona reticularis) to the organismal endocrine level via ceasing DHEA production (Fig. 5).

Senescence in general may also serve as a tumordefensive mechanism in the adrenal cortex. Benign lesions of the adrenal cortex, nodules, and adenomas are very common, but malignant lesions are extremely rare (Dobbie 1969, Mansmann et al. 2004). Recent advances in our understanding of melanocytic lesions have showed that melanocytes in common benign naevi undergo oncogene-induced senescence by the acquisition of BRAF mutations (Michaloglou et al. 2005). A parallel mechanism may prevent a higher incidence of progression of commonly observed adenomas or nodules to malignant tumors in the adrenal cortex.

\section{Future directions of research: therapeutic and diagnostic application}

Telomere dysfunction and TMM can cause initiation and maintenance of a malignant phenotype respectively. Current research has led to a model in which both processes play important roles in major events of carcinogenesis (Fig. 4). As outlined in this review, there is emerging evidence that this model holds true for adrenocortical neoplasms. The understanding and analyses of these mechanisms will further increase our knowledge of the participation of these processes in spontaneous human tumors and hereditary tumor syndromes, and, more importantly, may advance diagnosis and may facilitate the development of new therapies. 


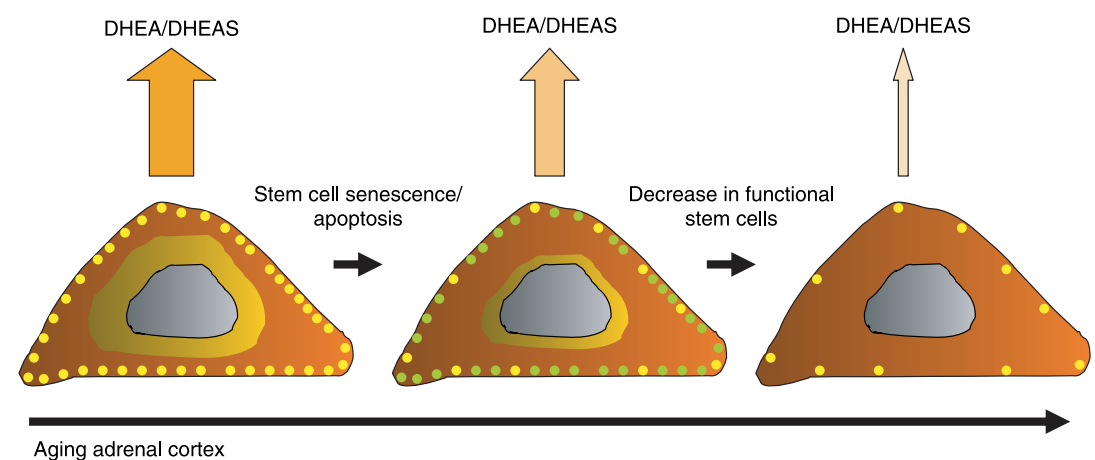

Figure 5 Proposed model of the aging adrenal cortex. This hypothesis links cellular aging/senescence to organ and organismal aging. The proposed stem cell compartment of the adrenal cortex (yellow circles) can be found in the periphery of the gland. As the normal adult adrenal cortex does not have any telomere length maintenance mechanisms, telomeres shorten over time and multiple cell cycles and lead to cellular senescence in the stem cell compartment (green circles). In the setting of a diminished stem cell pool, the vital functions of glucocorticoid and mineralocorticoid production in the zona glomerulosa and fasciculata are ensured at the expense of the zona reticularis (orange zone). This results in decreased DHEA/DHEAS secretion and may ultimately relay cellular aging, induced by telomere shortening, via organ aging to aging of the organism.

One hallmark of ACCs is their high genetic diversity, aneuploidy, and the presence of multiple amplifications and losses (Wajchenberg et al. 2000). All of these genomic changes could theoretically be explained by telomere dysfunction and repeated BFBs. Indeed, it may be a common pathomechanism in Li-Fraumeni patients who develop short telomeres and potentially telomere dysfunction (Tabori et al. 2007). There are also a significant number of DC patients, for whom no genetic mutation has been found: the future may reveal mutations in other genes of the shelterin complex. While at a first glance there is no connection between adrenal pathologies and DC, it is true that there are no thorough functional and morphological analyses of this organ in these patients. Interestingly, a recent publication has described patients with a Fanconi anemia phenotype and adrenocortical insufficiency, and it certainly would be informative to screen these kindred for potential shelterin gene mutations (O'Riordan et al. 2008).

The most important development for the future of ACC research is an international effort to collect large numbers of high-quality tissue samples, which then can be subjected to emerging new analytical methods. These methods are clearly not restricted to the analysis of telomere physiology-associated genes, but will give insights into general aspects of adrenocortical carcinogenesis. Bioinformatic methods will help to overcome sample shortage by combining an increasing number of available gene expression data sets. New technologies, such as deep sequencing technologies, will further complement traditional gene expression microarrays in transcriptome analysis and will also make it possible to more efficiently search for novel genomic mutations (Asmann et al. 2008). Another promising analytical method is the evaluation for single nucleotide polymorphisms (SNPs) and copy number variations. Many shelterin complex members harbor SNPs, some of which lead to amino acid changes on the protein level. SNPs may impact protein function or simply be associated with predisposition to cancer development or affect cancer characteristics directly (Engle et al. 2006).

It has become clear that TMMs are an important characteristic of ACC, and analyses for TMMs could be used as an adjunct diagnostic procedure to differentiate benign from malignant lesions. Furthermore, TMMs and telomeres may be used as a potential therapeutic target for tumor therapy. Several studies have used telomerase inhibitors as well as substances interfering with the telomere structure in preclinical cell culture and animal systems (Zimmermann \& Martens 2007). There are hopes that these strategies may specifically target stem cells within malignant lesions, which theoretically depend on TMMs to a larger extent than non-stem cells.

The last decade of research in the fast moving field of telomere and telomerase sciences has influenced the field of adrenocortical research significantly. The future will show how much of this fertile match between basic sciences and clinically oriented research can be translated from bench to bedside. Our hopes are that it will not only lead to a deeper understanding of disease processes but also to a real advancement in patient care.

\section{Declaration of interest}

There is no conflict of interest that could be perceived as prejudicing the impartiality of the research reported. 


\section{Funding}

T E was supported by a generous scholarship through the Garry Betty Foundation.

\section{Acknowledgements}

I would like to thank J. L. Garcia-Perez for critical reading of the manuscript, J. Heaton for structural and editorial advice, and the laboratory of G. D. Hammer in which I had the honor to conduct research contributing to the field of this review. I am also indebted to the Garry Betty Foundation that provided me with a generous scholarship for adrenocortical cancer research over the last two years.

\section{References}

Armanios M, Chen JL, Chang YPC, Brodsky RA, Hawkins A, Griffin CA, Eshleman JR, Cohen AR, Chakravarti A, Hamosh A et al. 2005 Haploinsufficiency of telomerase reverse transcriptase leads to anticipation in autosomal dominant dyskeratosis congenita. PNAS 102 15960-15964.

Artandi SE \& Attardi LD 2005 Pathways connecting telomeres and p53 in senescence, apoptosis, and cancer. Biochemical and Biophysical Research Communications 331 881-890.

Artandi SE, Chang S, Lee SL, Alson S, Gottlieb GJ, Chin L \& DePinho RA 2000 Telomere dysfunction promotes non-reciprocal translocations and epithelial cancers in mice. Nature 406 641-645.

Asmann YW, Wallace MB \& Thompson EA 2008 Transcriptome profiling using next-generation sequencing. Gastroenterology 135 $1466-1468$.

Attardi LD 2005 The role of p53-mediated apoptosis as a crucial antitumor response to genomic instability: lessons from mouse models. Mutation Research 569 145-157.

Bamberger CM, Else T, Bamberger AM, Frilling A, Beil FU, Allolio B \& Schulte HM 1999 Telomerase activity in benign and malignant adrenal tumors. Experimental and Clinical Endocrinology and Diabetes 107 272-275.

Baumann P \& Cech TR 2001 Potl, the putative telomere end-binding protein in fission yeast and humans. Science 292 1171-1175.

Beamer WG, Sweet HO, Bronson RT, Shire JGM, Orth DN \& Davisson MT 1994 Adrenocortical dysplasia: a mouse model system for adrenocortical insufficiency. Journal of Endocrinology 141 33-43.

Bellon M, Datta A, Brown M, Pouliquen JF, Couppie P, Kazanji M \& Nicot C 2006 Increased expression of telomere length regulating factors TRF1, TRF2 and TIN2 in patients with adult T-cell leukemia. International Journal of Cancer 119 2090-2097.

Blasco MA, Lee HW, Hande MP, Samper E, Lansdorp PM, DePinho RA \& Greider CW 1997 Telomere shortening and tumor formation by mouse cells lacking telomerase RNA. Cell 91 25-34.

Bodnar AG, Ouellette M, Frolkis M, Holt SE, Chiu CP, Morin GB, Harley CB, Shay JW, Lichtsteiner S \& Wright WE 1998 Extension of life-span by introduction of telomerase into normal human cells. Science 279 349-352.

Broccoli D, Smogorzewska A, Chong L \& de Lange T 1997 Human telomeres contain two distinct Myb-related proteins, TRF1 and TRF2. Nature Genetics 17 231-235.

Brown JP, Wei W \& Sedivy JM 1997 Bypass of senescence after disruption of p21CIP1/WAF1 gene in normal diploid human fibroblasts. Science 277 831-834.

Bryan TM, Englezou A, Dalla-Pozza L, Dunham MA \& Reddel RR 1997 Evidence for an alternative mechanism for maintaining telomere length in human tumors and tumor-derived cell lines. Nature Medicine 3 1271-1274.

Celli GB \& de Lange T 2005 DNA processing is not required for ATMmediated telomere damage response after TRF2 deletion. Nature Cell Biology 7 712-718.
Chiang YJ, Kim SH, Tessarollo L, Campisi J \& Hodes RJ 2004 Telomereassociated protein TIN2 is essential for early embryonic development through a telomerase-independent pathway. Molecular and Cellular Biology 24 6631-6634.

Chin L, Artandi SE, Shen Q, Tam A, Lee SL, Gottlieb GJ, Greider CW \& DePinho RA 1999 p53 deficiency rescues the adverse effects of telomere loss and cooperates with telomere dysfunction to accelerate carcinogenesis. Cell 97 527-538.

Choi J, Southworth LK, Sarin KY, Venteicher AS, Ma W, Chang W, Cheung P, Jun S, Artandi MK, Shah N et al. 2008 TERT promotes epithelial proliferation through transcriptional control of a Mycand Wnt-related developmental program. PLoS Genetics 4 e10.

Chong L, van Steensel B, Broccoli D, Erdjument-Bromage H, Hanish J, Tempst P \& de Lange T 1995 A human telomeric protein. Science 270 1663-1667.

Costa A, Daidone MG, Daprai L, Villa R, Cantú S, Pilotti S, Mariani L, Gronchi A, Henson JD, Reddel RR et al. 2006 Telomere maintenance mechanisms in liposarcomas: association with histologic subtypes and disease progression. Cancer Research 66 8918-8924.

Deng Y, Chan SS \& Chang S 2008 Telomere dysfunction and tumour suppression: the senescence connection. Nature Reviews. Cancer 8 $450-458$.

Dobbie JW 1969 Adrenocortical nodular hyperplasia: the ageing adrenal. Journal of Pathology 99 1-18.

Else T, Theisen BK, Wu Y, Hutz JE, Keegan CE, Hammer GD \& Ferguson DO 2007 Tpp1/Acd maintains genomic stability through a complex role in telomere protection. Chromosome Research $\mathbf{1 5}$ 1001-1013.

Else T, Giordano TJ \& Hammer GD 2008 Evaluation of telomere length maintenance mechanisms in adrenocortical carcinoma. Journal of Clinical Endocrinology and Metabolism 93 1442-1449.

Engle LJ, Simpson CL \& Landers JE 2006 Using high-throughput SNP technologies to study cancer. Oncogene 25 1594-1601.

Favara BE, Steele A, Grant JH \& Steele P 1991 Adrenal cytomegaly: quantitative assessment by image analysis. Pediatric Pathology 11 521-536.

Giordano TJ, Kuick R, Else T, Gauger PG, Vinco M, Bauersfeld J, Sanders D, Thomas DG, Doherty G \& Hammer G 2009 Molecular classification and prognostication of adrenocortical tumors by transcriptome profiling. Clinical Cancer Research 15 668-676.

Greider CW \& Blackburn EH 1987 The telomere terminal transferase of Tetrahymena is a ribonucleoprotein enzyme with two kinds of primer specificity. Cell $\mathbf{5 1} 887-898$.

Griffith JD, Comeau L, Rosenfield S, Stansel RM, Bianchi A, Moss H \& de Lange T 1999 Mammalian telomeres end in a large duplex loop. Cell 97 503-514.

Hakin-Smith V, Jellinek DA, Levy D, Carroll T, Teo M, Timperley WR, McKay MJ, Reddel RR \& Royds JA 2003 Alternative lengthening of telomeres and survival in patients with glioblastoma multiforme. Lancet 361 836-838.

Hande MP, Samper E, Lansdorp P \& Blasco MA 1999 Telomere length dynamics and chromosomal instability in cells derived from telomerase null mice. Journal of Cell Biology 144 589-601.

Hansemann DP 1891 Ueber Pathologische Mitosen. Virchows Archiv für Pathologische Anatomie und Physiologie und für Klinische Medizin 119 299-326.

Hanukoglu I 2006 Antioxidant protective mechanisms against reactive oxygen species (ROS) generated by mitochondrial P450 systems in steroidogenic cells. Drug Metabolism Reviews 38 171-196.

Harley CB, Futcher AB \& Greider CW 1990 Telomeres shorten during ageing of human fibroblasts. Nature 345 458-460.

Hayflick L 1965 The limited in vitro lifetime of human diploid cell strains. Experimental Cell Research 37 614-636.

Hayflick L \& Moorhead PS 1961 The serial cultivation of human diploid cell strains. Experimental Cell Research 25 585-621. 
He H, Multani AS, Cosme-Blanco W, Tahara H, Ma J, Pathak S, Deng Y \& Chang S 2006 POT1b protects telomeres from end-to-end chromosomal fusions and aberrant homologous recombination. EMBO Journal 25 5180-5190.

Heiss NS, Knight SW, Vulliamy TJ, Klauck SM, Wiemann S, Mason PJ, Poustka A \& Dokal I 1998 X-linked dyskeratosis congenita is caused by mutations in a highly conserved gene with putative nucleolar functions. Nature Genetics 19 32-38.

Hirano Y, Fujita K, Suzuki K, Ushiyama T, Ohtawara Y \& Tsuda F 1998 Telomerase activity as an indicator of potentially malignant adrenal tumors. Cancer 83 772-776.

Hockemeyer D, Daniels JP, Takai H \& de Lange T 2006 Recent expansion of the telomeric complex in rodents: two distinct POT1 proteins protect mouse telomeres. Cell 126 63-77.

Hockemeyer D, Palm W, Else T, Daniels JP, Takai KK, Ye JZ, Keegan CE, de Lange T \& Hammer GD 2007 Telomere protection by mammalian Pot1 requires interaction with Tpp1. Nature Structural and Molecular Biology 14 754-761.

Hornsby PJ 1995 Biosynthesis of DHEAS by the human adrenal cortex and its age-related decline. Annals of the New York Academy of Sciences 774 29-46.

Hornsby PJ 2002 Aging of the human adrenal cortex. Ageing Research Reviews 1 229-242.

Hornsby PJ 2007 Senescence as an anticancer mechanism. Journal of Clinical Oncology 25 1852-1857.

Houghtaling BR, Cuttonaro L, Chang W \& Smith S 2004 A dynamic molecular link between the telomere length regulator TRF1 and the chromosome end protector TRF2. Current Biology 14 1621-1631.

Hutz JE, Krause AS, Achermann JC, Vilain E, Tauber M, Lecointre C, McCabe ER, Hammer GD \& Keegan CE 2006 IMAGe association and congenital adrenal hypoplasia: no disease-causing mutations found in the ACD gene. Molecular Genetics and Metabolism 88 66-70.

Irving IM 1967 Exomphalos with macroglossia: a study of eleven cases. Journal of Pediatric Surgery 2 499-507.

Itahana K, Campisi J \& Dimri GP 2004 Mechanisms of cellular senescence in human and mouse cells. Biogerontology 5 1-10.

Jacobs JJ \& de Lange T 2005 pl6INK4a as a second effector of the telomere damage pathway. Cell Cycle 4 1364-1368.

Johnson JE, Varkonyi RJ, Schwalm J, Cragle R, Klein-Szanto A, Patchefsky A, Cukierman E, von Mehren M \& Broccoli D 2005 Multiple mechanisms of telomere maintenance exist in liposarcomas. Clinical Cancer Research 11 5347-5355.

Ju Z \& Rudolph KL 2006 Telomeres and telomerase in cancer stem cells. European Journal of Cancer 42 1197-1203.

Karlseder J, Broccoli D, Dai Y, Hardy S \& de Lange T 1999 p53- and ATM-dependent apoptosis induced by telomeres lacking TRF2. Science 283 1321-1325.

Karlseder J, Kachatrian L, Takai H, Mercer K, Hingorani S, Jacks T \& de Lange T 2003 Targeted deletion reveals an essential function for the telomere length regulator Trf1. Molecular and Cellular Biology 23 6533-6541.

Keegan CE, Hutz JE, Else T, Adamska M, Shah SP, Kent AE, Howes JM, Beamer WG \& Hammer GD 2005 Urogenital and caudal dysgenesis in adrenocortical dysplasia (acd) mice is caused by a splicing mutation in a novel telomeric regulator. Human Molecular Genetics 14 113-123.

Kim AC \& Hammer GD 2007 Adrenocortical cells with stem/progenitor cell properties: recent advances. Molecular and Cellular Endocrinology 265-266 10-16.

Kim NW, Piatyszek MA, Prowse KR, Harley CB, West MD, Ho PL, Coviello GM, Wright WE, Weinrich SL \& Shay JW 1994 Specific association of human telomerase activity with immortal cells and cancer. Science 266 2011-2015.

Kim SH, Kaminker P \& Campisi J 1999 TIN2, a new regulator of telomere length in human cells. Nature Genetics 23 405-412.
Kim AC, Reuter AL, Zubair M, Else T, Serecky K, Bingham NC, Lavery GG, Parker KL \& Hammer GD 2008 Targeted disruption of beta-catenin in Sf1-expressing cells impairs development and maintenance of the adrenal cortex. Development 135 2593-2602.

Kinoshita H, Ogawa O, Mishina M, Oka H, Okumura K, Yamabe H, Terachi T \& Yoshida O 1998 Telomerase activity in adrenal cortical tumors and pheochromocytomas with reference to clinicopathologic features. Urological Research 26 29-32.

Kipling D \& Cooke HJ 1990 Hypervariable ultra-long telomeres in mice. Nature 347 400-402.

Kondo T, Oue N, Yoshida K, Mitani Y, Naka K, Nakayama H \& Yasui W 2004 Expression of POT1 is associated with tumor stage and telomere length in gastric carcinoma. Cancer Research 64 523-529.

de Lange T 2005 Shelterin: the protein complex that shapes and safeguards human telomeres. Genes and Development 19 2100-2110.

Lazzerini Denchi E, Celli G \& de Lange T 2006 Hepatocytes with extensive telomere deprotection and fusion remain viable and regenerate liver mass through endoreduplication. Genes and Development 20 2648-2653.

Lee HW, Blasco MA, Gottlieb GJ, Horner JW II, Greider CW \& DePinho RA 1998 Essential role of mouse telomerase in highly proliferative organs. Nature 392 569-574.

Levy MZ, Allsopp RC, Futcher AB, Greider CW \& Harley CB 1992 Telomere end-replication problem and cell aging. Journal of Molecular Biology 225 951-960.

Li FP, Fraumeni JF Jr, Mulvihill JJ, Blattner WA, Dreyfus MG, Tucker MA \& Miller RW 1988 A cancer family syndrome in twenty-four kindreds. Cancer Research 48 5358-5362.

Li B, Oestreich S \& de Lange T 2000 Identification of human Rap1: implications for telomere evolution. Cell 101 471-483.

Lin X, Gu J, Lu C, Spitz MR \& Wu X 2006 Expression of telomereassociated genes as prognostic markers for overall survival in patients with non-small cell lung cancer. Clinical Cancer Research 12 $5720-5725$.

Liu Y, Snow BE, Hande MP, Yeung D, Erdmann NJ, Wakeham A, Itie A, Siderovski DP, Lansdorp PM, Robinson MO et al. 2000 The telomerase reverse transcriptase is limiting and necessary for telomerase function in vivo. Current Biology 10 1459-1462.

Liu D, O'Connor MS, Qin J \& Songyang Z 2004a Telosome, a mammalian telomere-associated complex formed by multiple telomeric proteins. Journal of Biological Chemistry 279 51338-51342.

Liu D, Safari A, O'Connor MS, Chan DW, Laegeler A, Qin J \& Songyang Z 2004b PTOP interacts with POT1 and regulates its localization to telomeres. Nature Cell Biology 6 673-680.

Lo AW, Sabatier L, Fouladi B, Pottier G, Ricoul M \& Murnane JP 2002 DNA amplification by breakage/fusion/bridge cycles initiated by spontaneous telomere loss in a human cancer cell line. Neoplasia 4 531-538.

Malkin D, Friend SH, Li FP \& Strong LC 1997 Germ-line mutations of the p53 tumor-suppressor gene in children and young adults with second malignant neoplasms. New England Journal of Medicine 336734.

Mannelli M, Gelmini S, Arnaldi G, Becherini L, Bemporad D, Crescioli C, Pazzagli M, Mantero F, Serio M \& Orlando C 2000 Telomerase activity is significantly enhanced in malignant adrenocortical tumors in comparison to benign adrenocortical adenomas. Journal of Clinical Endocrinology and Metabolism 85 468-470.

Mansmann G, Lau J, Balk E, Rothberg M, Miyachi Y \& Bornstein SR 2004 The clinically inapparent adrenal mass: update in diagnosis and management. Endocrine Reviews 25 309-340.

Michaloglou C, Vredeveld LC, Soengas MS, Denoyelle C, Kuilman T, van der Horst CMAM, Majoor DM, Shay JW, Mooi WJ \& Peeper DS 2005 BRAFE600-associated senescence-like cell cycle arrest of human naevi. Nature 436 720-724.

Midzak AS, Chen H, Papadopoulos V \& Zirkin BR 2009 Leydig cell aging and the mechanisms of reduced testosterone synthesis. Molecular and Cellular Endocrinology 299 23-31. 
Morin GB 1989 The human telomere terminal transferase enzyme is a ribonucleoprotein that synthesizes TTAGGG repeats. Cell $\mathbf{5 9}$ 521-529.

Muntoni A \& Reddel RR 2005 The first molecular details of ALT in human tumor cells. Human Molecular Genetics 14 R191-R196.

Murnane JP 2006 Telomeres and chromosome instability. DNA Repair 5 1082-1092.

Murnane JP \& Sabatier L 2004 Chromosome rearrangements resulting from telomere dysfunction and their role in cancer. BioEssays $\mathbf{2 6}$ 1164-1174.

O'Hagan RC, Chang S, Maser RS, Mohan R, Artandi SE, Chin L \& DePinho RA 2002 Telomere dysfunction provokes regional amplification and deletion in cancer genomes. Cancer Cell 2 149-155.

Olovnikov AM 1973 A theory of marginotomy. The incomplete copying of template margin in enzymic synthesis of polynucleotides and biological significance of the phenomenon. Journal of Theoretical Biology 41 181-190.

O'Riordan SM, Lynch SA, Hindmarsh PC, Chan LF, Clark AJ \& Costigan C 2008 A novel variant of familial glucocorticoid deficiency prevalent among the Irish Traveler population. Journal of Clinical Endocrinology and Metabolism 93 2896-2899.

Orlando C \& Gelmini S 2001 Telomerase in endocrine and endocrinedependent tumors. Journal of Steroid Biochemistry and Molecular Biology 78 201-214.

Parrinello S, Samper E, Krtolica A, Goldstein J, Melov S \& Campisi J 2003 Oxygen sensitivity severely limits the replicative lifespan of murine fibroblasts. Nature Cell Biology 5 741-747.

Poncet D, Belleville A, t'kint de Roodenbeke C, Roborel de Climens A, Ben Simon E, Merle-Beral H, Callet-Bauchu E, Salles G, Sabatier L, Delic J et al. 2008 Changes in the expression of telomere maintenance genes suggest global telomere dysfunction in B-chronic lymphocytic leukemia. Blood 111 2388-2391.

Prowse KR \& Greider CW 1995 Developmental and tissue-specific regulation of mouse telomerase and telomere length. PNAS 92 4818-4822.

Richter T \& von Zglinicki T 2007 A continuous correlation between oxidative stress and telomere shortening in fibroblasts. Experimental Gerontology 42 1039-1042.

Salhab M, Jiang WG, Newbold RF \& Mokbel K 2008 The expression of gene transcripts of telomere-associated genes in human breast cancer: correlation with clinico-pathological parameters and clinical outcome. Breast Cancer Research and Treatment 109 35-46.

Sarin KY, Cheung P, Gilison D, Lee E, Tennen RI, Wang E, Artandi MK, Oro AE \& Artandi SE 2005 Conditional telomerase induction causes proliferation of hair follicle stem cells. Nature 436 1048-1052.

Savage SA, Giri N, Baerlocher GM, Orr N, Lansdorp PM \& Alter BP 2008 TINF2, a component of the shelterin telomere protection complex, is mutated in dyskeratosis congenita. American Journal of Human Genetics 82 501-509.

Shelton DN, Chang E, Whittier PS, Choi D \& Funk WD 1999 Microarray analysis of replicative senescence. Current Biology 9 939-945.

Sun B, Huang Q, Liu S, Chen M, Hawks CL, Wang L, Zhang C \& Hornsby PJ 2004 Progressive loss of malignant behavior in telomerase-negative tumorigenic adrenocortical cells and restoration of tumorigenicity by human telomerase reverse transcriptase. Cancer Research 64 6144-6151.

Tabori U \& Malkin D 2008 Risk stratification in cancer predisposition syndromes: lessons learned from novel molecular developments in Li-Fraumeni syndrome. Cancer Research 68 2053-2057.

Tabori U, Nanda S, Druker H, Lees J \& Malkin D 2007 Younger age of cancer initiation is associated with shorter telomere length in Li-Fraumeni syndrome. Cancer Research 67 1415-1418.

Takai H, Smogorzewska A \& de Lange T 2003 DNA damage foci at dysfunctional telomeres. Current Biology 13 1549-1556.

Tan TY, Jameson JL, Campbell PE, Ekert PG, Zacharin M \& Savariravan R 2006 Two sisters with IMAGe syndrome: cytomegalic adrenal histopathology, support for autosomal recessive inheritance and literature review. American Journal of Medical Genetics, Part A 140 1778-1784.

Taylor RS, Ramirez RD, Ogoshi M, Chaffins M, Piatyszek MA \& Shay JW 1996 Detection of telomerase activity in malignant and nonmalignant skin conditions. Journal of Investigative Dermatology 106 759-765.

Teng L, Tucker O, Malchoff C, Vaughan ED Jr, Jacobson J \& Fahey TJ III 1998 Telomerase activity in the differentiation of benign and malignant adrenal tumors. Surgery 124 1123-1127.

Thomson JA, Itskovitz-Eldor J, Shapiro SS, Waknitz MA, Swiergiel JJ, Marshall VS \& Jones JM 1998 Embryonic stem cell lines derived from human blastocysts. Science 282 1145-1147.

Venteicher AS, Meng Z, Mason PJ, Veenstra TD \& Artandi SE 2008 Identification of ATPases pontin and reptin as telomerase components essential for holoenzyme assembly. Cell 132 945-957.

Vilain E, Le Merrer M, Lecointre C, Desangles F, Kay MA, Maroteaux P \& McCabe ER 1999 IMAGe, a new clinical association of intrauterine growth retardation, metaphyseal dysplasia, adrenal hypoplasia congenita, and genital anomalies. Journal of Clinical Endocrinology and Metabolism 84 4335-4340.

Vulliamy T, Marrone A, Goldman F, Dearlove A, Bessler M, Mason PJ \& Dokal I 2001 The RNA component of telomerase is mutated in autosomal dominant dyskeratosis congenita. Nature 413 432-435.

Wajchenberg BL, Albergaria Pereira MA, Medonca BB, Latronico AC, Campos Carneiro P, Alves VA, Zerbini MC, Liberman B, Carlos Gomes G \& Kirschner MA 2000 Adrenocortical carcinoma: clinical and laboratory observations. Cancer 88 711-736.

Weng NP, Levine BL, June CH \& Hodes RJ 1996 Regulated expression of telomerase activity in human T lymphocyte development and activation. Journal of Experimental Medicine 183 2471-2479.

Wright WE, Piatyszek MA, Rainey WE, Byrd W \& Shay JW 1996 Telomerase activity in human germline and embryonic tissues and cells. Developmental Genetics 18 173-179.

Wu L, Multani A, He H, Cosme-Blanco W, Deng Y, Deng J, Bachilo O, Pathak S, Tahara H \& Bailey S 2006 Potl deficiency initiates DNA damage checkpoint activation and aberrant homologous recombination at telomeres. Cell 126 49-62.

Yang L, Suwa T, Wright WE, Shay JW \& Hornsby PJ 2001 Telomere shortening and decline in replicative potential as a function of donor age in human adrenocortical cells. Mechanisms of Ageing and Development 122 1685-1694.

Yashima K, Maitra A, Rogers BB, Timmons CF, Rathi A, Pinar H, Wright WE, Shay JW \& Gazdar AF 1998 Expression of the RNA component of telomerase during human development and differentiation. Cell Growth and Differentiation 9 805-813.

Ye JZ, Donigian JR, van Overbeek M, Loayza D, Luo Y, Krutchinsky AN, Chait BT \& de Lange T $2004 a$ TIN2 binds TRF1 and TRF2 simultaneously and stabilizes the TRF2 complex on telomeres. Journal of Biological Chemistry 279 47264-47271.

Ye JZ, Hockemeyer D, Krutchinsky AN, Loayza D, Hooper SM, Chait BT \& de Lange T 2004b POT1-interacting protein PIP1: a telomere length regulator that recruits POT1 to the TIN2/TRF1 complex. Genes and Development 18 1649-1654.

Zajicek G, Ariel I \& Arber N 1986 The streaming adrenal cortex: direct evidence of centripetal migration of adrenocytes by estimation of cell turnover rate. Journal of Endocrinology 111 477-482.

Zanaria E, Muscatelli F, Bardoni B, Strom TM, Guioli S, Guo W, Lalli E, Moser C, Walker AP, McCabe ER et al. 1994 An unusual member of the nuclear hormone receptor superfamily responsible for X-linked adrenal hypoplasia congenita. Nature 372 635-641.

Zimmermann S \& Martens UM 2007 Telomeres and telomerase as targets for cancer therapy. Cellular and Molecular Life Sciences 64 906-921.

Received in final form 17 April 2009

Accepted 1 May 2009

Made available online as an Accepted Preprint 1 May 2009 